\title{
Height, surface firmness, and visual reference effects on balance control
}

\author{
P Simeonov, H Hsiao
}

\begin{abstract}
Objectives-To investigate the effects of height, surface firmness, and visual reference on standing balance in construction workers.

Design-Controlled laboratory study with balanced repeated measures.

Participants-Twenty four construction workers.

Setting-Test subjects performed standing tasks at ground level as well as at $3 \mathrm{~m}$ and $9 \mathrm{~m}$ high balconies on firm or deformable surfaces with close visual references included or excluded from their visual field.

Methods-Standing balance was determined from center of pressure as measured by a force platform. Dependent variables were root mean square of sway in medial-lateral and anterior-posterior directions, area of sway, and velocity of sway.

Results-Heights without close visual references significantly increased all sway parameters. The effect of height in conditions without close visual references increased dramatically on deformable surfaces.

Conclusions-Elevated work environments and deformable work surfaces negatively affect balance and may be associated with increased risk of fall incidents. Appropriate close visual references increase the ability to maintain balance.

(Injury Prevention 2001;7(Suppl I):i50-53)
\end{abstract}

Keywords: falls; balance control; visual references; occupational injury

Falls are the leading cause of work related death in the United States construction industry. ${ }^{1}$ In 1998, approximately 372 construction workers lost their lives in falls from elevation in the United States' ${ }^{2}$; an additional 21081 serious fall injuries occurred that resulted in days away from work. ${ }^{3}$ The consequences of these injuries are extremely severe, requiring long periods of treatment and resulting in substantial medical cost. ${ }^{45}$

Loss of balance has been identified as one of the triggering events for fall incidents in construction. In an analysis of 55 fatal falls from roofs, loss of balance while moving materials or while operating or moving equipment was a common factor among cases. ${ }^{6}$ Most of the fatal falls from scaffolding and building girders that occurred during 1997 were also associated with loss of balance. ${ }^{7}$ To maintain balance the human brain uses information from three sensory systems: visual, vestibular and somatosensory (for example, from the forces of the muscles and the pressure under the feet). The risk of falling increases with the number of conditions (personal, task related, and environmental) that degrade the sensory information needed for balance control. ${ }^{8}$ Workers in construction perform a variety of tasks for extended periods of time on elevated work surfaces, and frequently on deformable or unstable surfaces. These conditions may affect balance and increase the risk of falls.

The objective of this study was to investigate the effect of height, surface firmness, and visual cues on the balance in construction workers.

\section{Methods}

PARTICIPANTS

The test subjects were 24 male construction workers with at least six months' experience of working at heights. Participants in the study were recruited via classified ads and letters to the local unions. They were between 21 and 57 years old with an average age of 31 years, average body weight $90.5 \mathrm{~kg}$ (95\% confidence interval (CI) 84.1 to 96.9 ), and average height $179 \mathrm{~cm}$ (95\% CI 176.8 to 182.3). Exclusion criteria for study participation included: acrophobia, height vertigo, history of dizziness, neurological disorder, abnormal vision, and uncorrected vision. The experimental protocol for the study was approved by the Institutional Review Board at the National Institute for Occupational Safety and Health (NIOSH). All participants gave informed consent before the study and were compensated for their time.

EXPERIMENTAL CONDITIONS

The study used a repeated measures design with three independent variables: height, surface firmness, and visual reference. Twelve treatments $(3 \times 2 \times 2)$ were assigned to each subject and were balanced to control for order effects. Two baseline tests with eyes closed while standing on firm and deformable surfaces were also performed. Three consecutive trials per experimental condition were done. For each trial, the test subjects stood (with heels together and feet angled at $30^{\circ}$, hands by the hips, and looking straight forward) and the data were collected for 30 seconds. A seated rest period of three minutes was provided between experimental conditions to reduce the possibility of fatigue. The participants were tested for approximately three hours.

\section{Height}

Tests were conducted on elevated surfaces in the NIOSH laboratory in Morgantown, West 


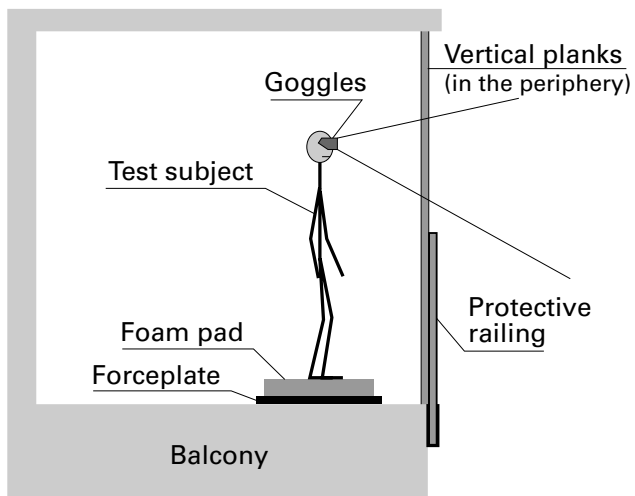

Figure 1 Experimental setup to examine balance control.

Virginia. The laboratory is equipped with $3 \mathrm{~m}$ and $9 \mathrm{~m}$ high balconies (fig 1). These balconies are equipped with metal protective railings, thus minimizing the psychophysiological effects from elevation exposure in this study. Tests at ground level $(0 \mathrm{~m})$ were also conducted.

\section{Surface firmness}

Two levels of surface firmness were evaluated-a rigid support corresponding to a firm and stable work surface and a deformable support simulating unstable work surfaces. A foam pad with a thickness of $10 \mathrm{~cm}$ and density $0.080 \mathrm{~g} / \mathrm{cm}^{3}$ was used to simulate an unstable surface. Subjects stood either on a foam pad placed on a rigid surface or on a rigid support without the foam pad. The subject wore safety shoes and socks provided by the laboratory.

\section{Visual reference}

To simulate an elevated workplace without close visual references, the test subjects wore goggles that restricted their visual field to an approximate $50^{\circ}$ angle in the vertical direction and an approximate $95^{\circ}$ angle in the horizontal direction. With goggles the test subjects were not able to see the protective railing, the edges of the balconies and the close visual references that were constructed for the study. The closest objects that could be seen were at a distance of more than $5 \mathrm{~m}$. In the alternative test condition (without goggles), the test subjects could see everything in the periphery of their visual field. At all height levels the closest visual references in the periphery were two vertical planks $(4 \times 8$ $\mathrm{cm})$ symmetrically located $76 \mathrm{~cm}$ from the eye and angled $53^{\circ}$ from gaze direction. At the ground level the test subjects were standing in front of a white poster with random contrasts (black rectangles of different shape, size, and orientation) at a distance of $120 \mathrm{~cm}$. In addition, the experimental design included baseline tests with eyes closed.

INSTRUMENTATION

The equipment for the center of pressure measurements was the portable strain gaugetype force platform Accusway (Advanced Mechanical Technologies, Inc, Watertown, MA, USA), which was capable of measuring forces and moments along three orthogonal axes. Data was collected with a portable personal computer at $50 \mathrm{~Hz}$ frequency. Swaywin (Advanced Mechanical Technologies, Inc, Watertown, MA, USA) software was used to calculate the variables describing the body's center of pressure movement.

\section{DEPENDENT VARIABLES}

Four dependent variables derived from center of pressure measurements were used to quantitatively describe sway and determine postural stability. The variables are root mean square (RMS) of center of pressure displacement in medial-lateral direction and anterior-posterior direction, sway area calculated as the center of pressure $95 \%$ confidence ellipse, and the mean velocity of center of pressure displacement. RMS represents a suitable measure for average body sway over a certain period and allows an easy comparison to be made between the effects of different experimental conditions. ${ }^{9}$ Sway velocity is considered to be a valid measure of postural stability and is associated with risk of falling. ${ }^{10}$

\section{STATISTICAL METHODS}

Analysis of variance using the general linear model procedure in SAS software (SAS Institute Inc, Cary, NC, USA) was used to determine differences between the experimental conditions. Dependent variables were assessed assuming within subject variation as a random effect and employing the NewmanKeuls procedure to adjust for multiple comparisons. Post hoc comparisons were performed using the appropriate error term under the assumptions described above.

\section{Results}

RMS OF ANTERIOR-POSTERIOR SWAY

RMS of anterior-posterior sway analysis showed a significant three way interaction for height, surface firmness and visual reference $(\mathrm{p}<0.0001)$ (see table 1). Height at conditions

Table 1 Analysis of variance table for the significant effects (and interactions) on balance control of varying height, surface firmness, and visual reference

\begin{tabular}{|c|c|c|c|c|c|c|c|c|c|}
\hline \multirow[b]{2}{*}{ Source } & \multirow[b]{2}{*}{$d f$} & \multicolumn{2}{|c|}{$R M S A P^{\star}$ sway } & \multicolumn{2}{|c|}{ RMS ML† sway } & \multicolumn{2}{|c|}{ Sway area } & \multicolumn{2}{|c|}{ Sway velocity } \\
\hline & & $F$ value & p Value & $F$ value & $p$ Value & $F$ value & p Value & $F$ value & p Value \\
\hline \multicolumn{10}{|l|}{ Main effects } \\
\hline Height & 2 & 58.24 & $<0.0001$ & 39.51 & $<0.0001$ & 65.77 & $<0.0001$ & 30.54 & $<0.0001$ \\
\hline Surface firmness & 1 & 139.13 & $<0.0001$ & 159.64 & $<0.0001$ & 162.11 & $<0.0001$ & 127.79 & $<0.0001$ \\
\hline Visual reference & 1 & 198.74 & $<0.0001$ & 33.73 & $<0.0001$ & 64.29 & $<0.0001$ & 124.49 & $<0.0001$ \\
\hline \multicolumn{10}{|l|}{ Interactions } \\
\hline Height $\times$ surface firmness & 2 & 14.81 & $<0.0001$ & 20.14 & $<0.0001$ & 43.16 & $<0.0001$ & 59.24 & $<0.0001$ \\
\hline Height $\times$ visual reference & 2 & 73.14 & $<0.0001$ & 3.08 & ns & 71.58 & $<0.0001$ & 32.93 & $<0.0001$ \\
\hline Surface firmness $\times$ visual reference & 1 & 79.45 & $<0.0001$ & 34.36 & $<0.0001$ & 114.66 & $<0.0001$ & 92.84 & $<0.0001$ \\
\hline Height $\times$ surface firmness $\times$ visual reference & 2 & 21.53 & $<0.0001$ & 17.63 & $<0.0001$ & 60.90 & $<0.0001$ & 13.29 & $<0.0001$ \\
\hline
\end{tabular}

${ }^{\star}$ RMS AP sway $=$ root mean square anterior-posterior sway.

tRMS ML sway = root mean square medial-lateral sway. 

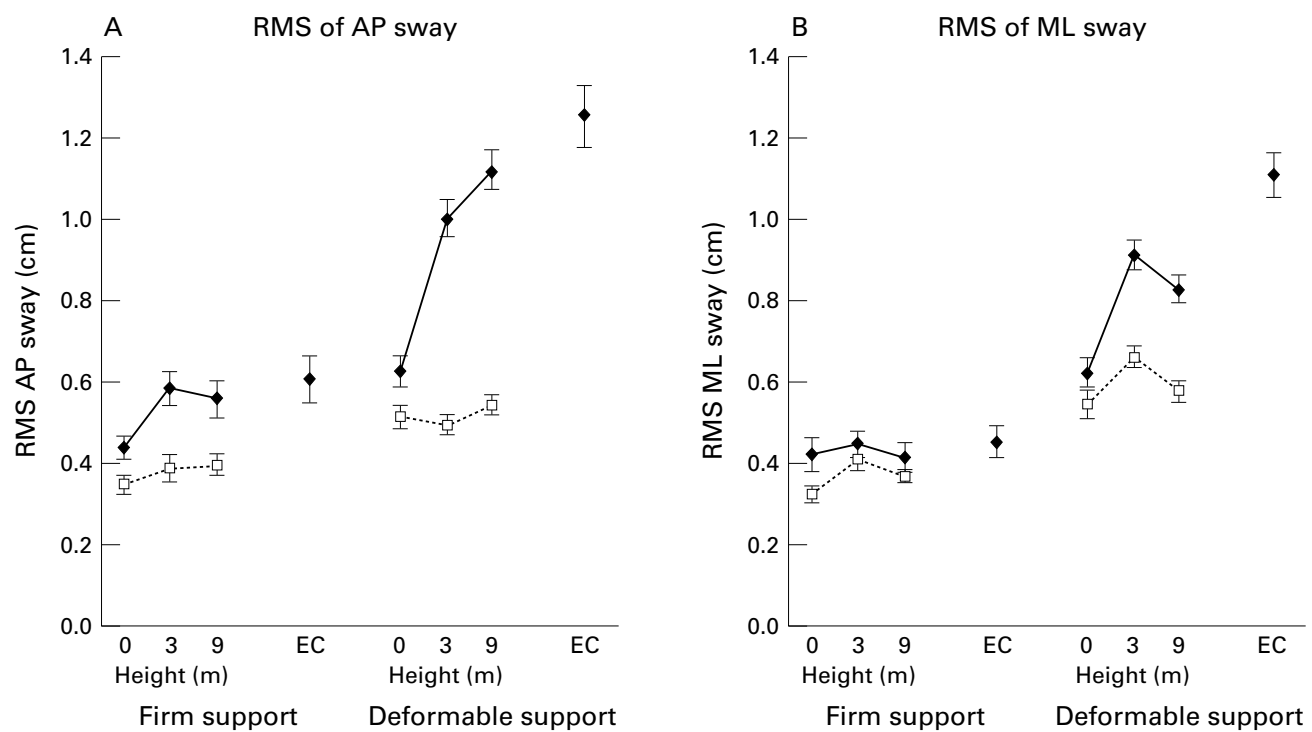

Figure 2 Effects of height and close visual reference on balance control, as measured by root mean square (RMS) of $(A)$ anterior-posterior $(A P)$ sway and (B) medial-lateral (ML) sway, by firm or deformable support surface. Solid line with diamonds: condition without close visual references in the peripheral visual field (with goggles) and dashed line with squares: close visual references in peripheral field (no goggles); EC = eyes closed. Error bars indicate standard error of the mean.

without close visual references significantly increased anterior-posterior sway on firm support at $3 \mathrm{~m}$ and $9 \mathrm{~m}$ at the rates of $33 \%$ and $27 \%$, respectively (fig $2 \mathrm{~A}$ ). This effect increased substantially and was statistically significant for deformable surfaces at $3 \mathrm{~m}$ $(60 \%)$ and $9 \mathrm{~m}(79 \%)$. The deformable surface dramatically increased the anterior-posterior sway at all heights $(72 \%$ at $3 \mathrm{~m}$ and $101 \%$ at 9 $\mathrm{m})$ at conditions without close visual references. Close visual references significantly reduced the anterior-posterior sway associated with height and deformable surface.

RMS OF MEDIAL-LATERAL SWAY

RMS of medial-lateral sway analysis indicated a significant three way interaction of height, surface firmness, and visual reference $(\mathrm{p}<0.0001)$ (see table 1). Height at conditions

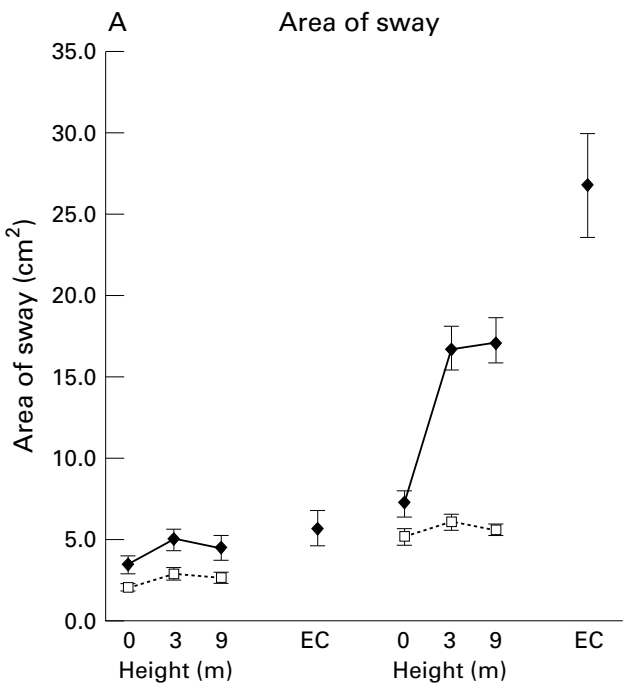

Firm support

Deformable support without close visual references significantly increased medial-lateral sway on soft support $(47 \%$ at $3 \mathrm{~m}$ and $33 \%$ at $9 \mathrm{~m}$ ) (fig $2 \mathrm{~B}$ ). The effect was not significant on firm support. Deformable surface dramatically increased medial-lateral sway at $3 \mathrm{~m}(104 \%)$ and $9 \mathrm{~m}$ $(101 \%)$ heights without close visual references. Close visual references substantially reduced medial-lateral sway at both $3 \mathrm{~m}$ and $9 \mathrm{~m}$ heights on deformable support.

AREA OF SWAY

Area of sway analysis showed a significant three way interaction for height, surface firmness, and visual reference $(\mathrm{p}<0.0001)$ (see table 1$)$. Height significantly increased area of sway at 3 $\mathrm{m}(44 \%)$ and $9 \mathrm{~m}(30 \%)$ in conditions without close visual references and on firm support (fig 3A). The effect of height on area of sway under

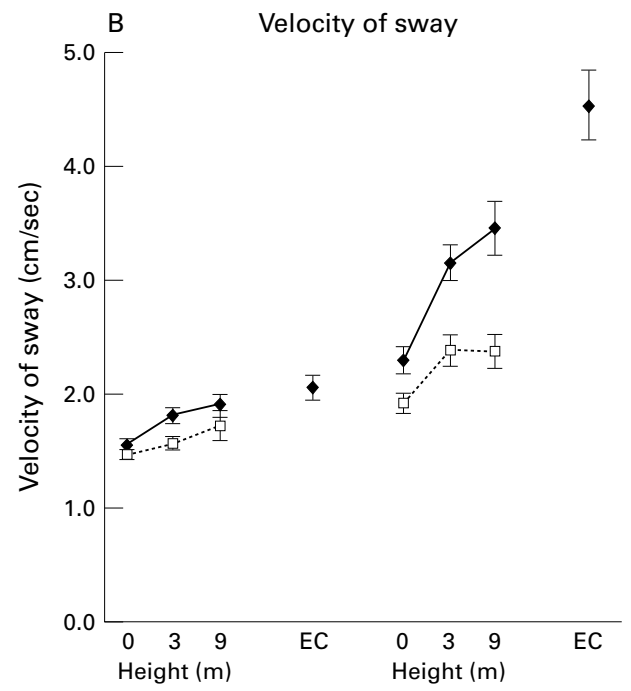

Firm support Deformable support

ences on firm and deformable supp goggles) and dashed line with squares: condition with close visual references in the peripheral visual field (without goggles); $E C=$ eyes closed. Error bars indicate standard error of the mean. 
the same visual conditions dramatically increased on deformable surface and was statistically equivalent at $3 \mathrm{~m}$ and $9 \mathrm{~m}$ height. Deformable surfaces significantly increased the area of sway in all experimental conditions, especially when the tests were performed at elevation. Close visual references significantly reduced the destabilizing effects of height and deformable surface, as measured by area of sway.

\section{VELOCITY OF SWAY}

Velocity of sway analysis also showed a significant three way interaction of height, surface firmness, and visual reference $(\mathrm{p}<0.0001)$ (see table 1). Height at conditions without close visual references significantly increased velocity of sway on firm surfaces and the effects were statistically equivalent at $3 \mathrm{~m}(17 \%)$ and $9 \mathrm{~m}$ $(21 \%)$ (fig 3B). This effect considerably increased on deformable surface $(37 \%$ at $3 \mathrm{~m}$ and $51 \%$ at $9 \mathrm{~m}$ ). Close visual references reduced velocity of sway related to elevation and deformable surface.

\section{Discussion}

The present study demonstrated that height, surface firmness, and close visual reference significantly affect balance control. Workers in construction are frequently exposed to elevations. At any height, when a worker directs his eyes to a distant target - that is, to the ground, a tree, or a house, his field of vision may not include close visual references. The results were similar at varying heights ( $3 \mathrm{~m}$ or $9 \mathrm{~m}$ ), most likely because each height was equally deficient in close visual structures. Consistently, other studies suggested that height vertigo is associated with postural instability in conditions deficient in close visual references, and stabilization of posture occurs only when visual references are within $2.5 \mathrm{~m} .^{911}{ }^{12}$ The effect of height on medial-lateral sway at $9 \mathrm{~m}$ was relatively smaller than the same effect at 3 $\mathrm{m}$; it is likely that a part of the ceiling structure of the lab might have been included in the visual field of some of the test subjects, providing reference for lateral stabilization.

The study results showed that deformable surface amplify the effect of visual reference on balance. The mechanism of balance control requires information from at least two of the three sensory systems (vestibular, somatosensory, and visual) to successfully maintain balance. ${ }^{13}$ On firm support, the mechanism of balance control relies mainly on somatosensory input (for example, change of pressure under the feet). However, in conditions of deformable support, the visual information becomes critical for control of balance. In general, any condition that reduces somatosensory input will significantly increase the role of visual information for balance control. During construction work at elevation, workers frequently use temporary work surfaces/structures as foot supports. These structures may bend, flex, yield, or compress. In such conditions the role of visual information will be critical for balance control to avoid falls.
The results indicated that close visual references reduced instability related to elevations and significantly improved balance on deformable support. The effect of close visual references was stronger on anterior-posterior sway than on medial-lateral sway. This difference more likely resulted from the peripheral position of the close visual references in this study (that is, $53^{\circ}$ off central gaze direction). It has been reported that central vision was more efficient than peripheral vision for regulating medial-lateral sway, whereas peripheral vision was more efficient than central vision in regulating anterior-posterior body sway. ${ }^{14}$

\section{Conclusions}

Exposure to environments without close visual references such as working at elevations has a significant effect on ability to maintain balance. This effect is strongly pronounced in conditions with non-stable work surfaces.

\section{Recommendations}

Workers should be aware of the factors that affect balance control when working at elevations. Whenever practical, visual references should be added to serve as a tool to maintain balance and reduce the potential for falls. The visual reference can be a protective railing, which can act as a direct protective barrier as well as a visual stabilizer. Temporary structural elements such as vertical bars and permanent structures such as lightning poles, antennae, ventilation pipes and chimneys, could also serve as visual anchors when working at heights.

1 Bell CA, Stout NS. Fatal injuries in construction. Excel 1990;4:5-7.

2 Bureau of Labor Statistics. Census of fatal occupational injuries data. Event or exposure by major private industry division, 1998. Washington, DC: US Department of Labor, Bureau of Labor Statistics, 1999 (http://stats.bls.gov/ oshcfoil.htm\#).

3 Bureau of Labor Statistics. Case and demographic characteristics for workplace injuries and illnesses involving days away from work, 1998. Washington, DC: US Department of Labor, Bureau of Labor Statistics, 2000: table R68 (http:// Bureau of Labor Statistics,
stats.bls.gov/oshc d98.htm\#).

4 Gillen M, Faucett J, Beaumont J, et al. Injury severity associated with nonfatal construction falls. Am f Ind Med 1997; 32:647-55.

5 Parsons TJ, Pizatella TJ. Safety analysis of high risk activities within the roofing industry. (Technical report, NTIS PB-85163236.) Springfield, Virginia: National Technical Information Service, 1985

6 Cloe W. Occupational fatalities related to roofs, ceilings and floors as found in reports of OSHA fatality/catastrophe investigations. Washington, DC: Occupational Safety and Health gations. Washington, DC: Occupational Safety and

7 Administration, US Department of Labor, 1979 . Webster T. Workpalce falls. Compensation and working condi-
tions. Washington, DC: Bureau of Labor Statistics, Spring tions. Washingt $28-38$.

8 Tinetti ME, Speechley M. Prevention of falls among the elderly. $N$ Engl F Med 1989;320:1055-9.

9 Bles W, Kapteyn T, Brandt T, et al. The mechanism of physiological height vertigo. II. Posturography. Acta Otolaryngol 1980;89:534-40.

10 Robbins S, Waked E, Krouglicof N. Improving balance. $f$ Am Geriatr Soc 1998;46:1363-70.

11 Brandt T, Arnold F, Bles W, et al. The mechanism of physiological height vertigo. I. Theoretical approach and psychophysics. Acta Otolaryngol 1980;89:513-23.

psychophysics. Acta Otolaryngol 1980;89:513-23.
12 Paulus W, Straube A, Brandt T. Visual stabilization of posture. Physiological stimulus characteristics and clinical ture. Physiological stimulus charac

13 Diener HC, Dichgans J. On the role of vestibular, visual and somatosensory information for dynamic postural control in humans. Prog Brain Res 1988;76:253-62

14 Nougier V, Bard C, Fleury M, et al. Contribution of central and peripheral vision to the regulation of stance. Gait $\mathcal{E}$ Posture 1997;5:34-41. 